\title{
The Influence of Microstructure and Mechanical Resistance on the Shape Memory of Ecae Processed Stainless Fe-Mn-Si-Cr-Ni-Co Steel
}

\author{
Karine Andrea Käfer ${ }^{\star}{ }^{\oplus}$, Heide Heloise Bernardi ${ }^{b}$, Osmar de Sousa Santos ${ }^{a}$, Larissa Otubo ${ }^{c}$, Nelson \\ Batista de Lima ${ }^{c}$, Jorge Otubo ${ }^{a}($ (] \\ ${ }^{a}$ Instituto Tecnológico de Aeronáutica - ITA, Praça Marechal Eduardo Gomes 50, CEP: 12.228-900, \\ São José dos Campos, SP, Brasil \\ ${ }^{b}$ Faculdade de Tecnologia de São José dos Campos - Prof. Jessen Vidal, Avenida Cesare Mansueto \\ Giulio Lattes, 1350 - Eugênio de Melo, CEP 12247-014, São José dos Campos, SP, Brasil \\ 'Instituto de Pesquisas Energéticas e Nucleares - IPEN, Avenida Lineu Prestes 2242, Cidade \\ Universitária, CEP 05508-000, São Paulo, SP, Brasil
}

Received: October 24, 2017; Revised: May 30, 2018; Accepted: July 09, 2018

\begin{abstract}
In the current work, XRD, SEM, EBSD and TEM techniques were used to evaluate the microstructure of stainless Fe-Mn-Si-Cr-Ni-Co shape memory steel processed by ECAE and annealed for one hour at temperatures ranging from $650^{\circ} \mathrm{C}$ to $950^{\circ} \mathrm{C}$. The results were then correlated with the mechanical and shape-memory properties of the steel. It was observed that the samples containing large grains and a microstructure free of defects or precipitates presented a high volume fraction of multi-variant thermal martensite and stress-induced martensite, resulting in good shape recovery, owing to the memory effect. The grain refinement and precipitation of second-phase particles decreased the volume fraction and number of martensite variants and considerably increased the mechanical resistance, enhancing the elastic shape recovery. It was shown that shape memory properties were essentially related to the mechanical resistance of the matrix, which in turn was related to the microstructure.
\end{abstract}

Keywords: Stainless shape memory steel, ECAE, grain size, second-phase particles, martensitic transformation, SME.

\section{Introduction}

Fe-based stainless shape memory steels exhibit a straininduced $\gamma(\mathrm{fcc}) \leftrightarrow \varepsilon$ (hcp) martensitic transformation, which is reversed by heating, promoting shape recovery ${ }^{1}$. They present promising characteristics, such as low fabrication costs and good mechanical and corrosion resistance. Therefore, many efforts have been made to create practical applications for them as smart materials ${ }^{2,3}$.

According to Otsuka and Wayman ${ }^{1}$, two important conditions need to be satisfied in order to obtain good shape-memory properties in Fe-based alloys. First, the deformation should occur only by stress-induced martensitic transformation (SIMT), without the occurrence of permanent slip, and second, the martensite-martensite and martensiteaustenite interfaces must be mobile, which means that the same Shockley partial dislocations must act in the direct and reverse martensitic transformations.

Based on these considerations, it was proposed that strengthening the austenite parent phase by solid solution ${ }^{4,5}$ and/or precipitation hardening ${ }^{6-11}$ could be an efficient mechanism to suppress the occurrence of permanent slip, thereby improving the shape memory properties. Accordingly, apart from preventing permanent slip, matrix strengthening could result in a back stress at the tip of the martensite plates, assisting the reverse movement of the Shockley partial dislocations during heating ${ }^{5,6}$. Moreover, second-phase particles uniformly distributed in the matrix would act as preferential nucleation sites for domains of thin $\varepsilon$ martensite plates, increasing phase reversibility $6,7,8$.

However, the results of our previous work ${ }^{12}$ indicated a different interpretation for the effect of matrix strengthening on the shape memory effect. It was observed that the Equal Channel Angular Extrusion (ECAE), followed by annealing treatments in temperatures ranging from $650^{\circ} \mathrm{C}$ to $850^{\circ} \mathrm{C}$, significantly increased the mechanical resistance of the stainless $\mathrm{Fe}-\mathrm{Mn}$-Si-Cr-Ni-Co-Ti shape memory steel, owing to grain refinement and the precipitation of second-phase particles. These microstructural characteristics led to an increase in the total shape recovery compared to the solution treated condition, reaching their highest values at maximum hardness. Nevertheless, on separating the total shape recovery as an elastic shape recovery (upon unloading) and shape recovery owing to the memory effect (upon heating), it was noticeable that such improvement was related to a remarkable increase in the elastic shape recovery. Moreover, as the annealing temperature was increased, elastic shape recovery decreased and the shape memory effect increased, thus reversing the above-mentioned behaviour. Eventually, the maximum shape recovery might coincide with maximum strength, leading to the conclusion that high strength would result in high shape memory effect. 
These results suggest that, for a better understanding, the total shape recovery should be separated into elastic shape recovery and shape recovery owing to memory effect and the contribution of each component should be correlated with the microstructure and mechanical resistance of the matrix. The aim of the current work is to further explore the above idea, evaluating the effect of mechanical strengthening due to grain refinement and second phase particles on the shape memory properties. The alloy used in this study was a stainless Fe-Mn-Si-Cr-Ni-Co shape memory steel, which showed an improvement in the shape memory effect as the grain size decreased from $80 \mu \mathrm{m}$ to $35 \mu \mathrm{m}^{13}$. The microstructures were handled by ECAE thermomechanical processing in order to produce fine grains, and techniques such as XRD, SEM, EBSD, TEM and compression tests were used to characterise the microstructural features and mechanical and shape memory properties.

\section{Experimental Procedure}

The stainless Fe-8.26Mn-5.25Si-12.80Cr-5.81Ni-11.84Co (in wt \%) shape memory steel ingot was produced by vacuum induction melting (VIM) in an argon atmosphere. The ingot was hot-forged and hot-rolled as described elsewhere ${ }^{12,13}$. For the ECAE processing, samples with $7 \mathrm{~mm} \times 7 \mathrm{~mm} x$ $70 \mathrm{~mm}$ were machined from the bars, solution treated (ST) at $1050^{\circ} \mathrm{C}$ for one hour and then quenched in water at room temperature. The samples were mounted in an ECAE die with a square cross-section of $7 \mathrm{~mm} \times 7 \mathrm{~mm}\left(\Phi=120^{\circ}, \psi=0^{\circ}\right)$ and extruded at $250^{\circ} \mathrm{C}$ and strain rate of $5 \mathrm{~mm} / \mathrm{min}$ in an Instron Testing Machine (5500R), coupled with an environment chamber. For the second pass, the samples were rotated $90^{\circ}$ along the longitudinal axis and then extruded once more, using the same processing conditions (Route $\mathrm{Bc})^{14}$. After two ECAE passes the samples were annealed for one hour at temperatures ranging from $650^{\circ} \mathrm{C}$ to $950^{\circ} \mathrm{C}$. The samples were identified as: ST (Solution Treated); ST + 2ECAE; and $\mathrm{ST}+2 \mathrm{ECAE}+$ Annealing Temperature.

For the microstructural observations, the samples were prepared using conventional metallographic procedures and etched using a glyceregia solution $(3 \mathrm{ml} \mathrm{HCl}+2 \mathrm{ml}$ glycerine $+1 \mathrm{ml} \mathrm{HNO}_{3}$ ). The grain size was estimated according to ASTM E112-13 standard ${ }^{15}$. IMAGE J image analysis software was used to quantify the area fraction and average size of second-phase particles ${ }^{16}$. In preparation for EBSD analysis, the polishing procedure was extended to include final polishing in a solution of colloidal silica for 30 minutes. The observations were performed using an FEI - Quanta $650 \mathrm{~F}$ field-emission electron microscope, equipped with a high-resolution EBSD detector, on the surface normal to the extrusion direction. EBSD results were analysed using Oxford Channel 5 software. X-Ray Diffraction (XRD) analyses were done in a Rigaku Multiflex X-ray diffractometer, using $\mathrm{Cu}$ $\mathrm{K} \alpha$ radiation, scanning from $20^{\circ}$ to $100^{\circ}$ at $0.5^{\circ} / \mathrm{min}$. The
Materials Analysis Using Diffraction Software (MAUD) was used to estimate the volume fraction of thermal and stressinduced martensite ${ }^{17}$. Transmission electron microscopy (TEM) samples were prepared using a Gatan PIPS ion-beam milling, with an incidence angle of $10^{\circ}$, a beam energy of $5 \mathrm{keV}$ and the rotation speed of $3 \mathrm{rpm}$. The observations were carried out in a JEOL JEM 2100 transmission electron microscope, operating at $200 \mathrm{kV}$.

Mechanical and shape memory properties were evaluated by compression tests performed in a 5500R Instron Testing Machine. Samples with $7 \mathrm{~mm} \times 7 \mathrm{~mm}$ x $17 \mathrm{~mm}$ were subjected to $4 \%$ compressive strain at room temperature. Elastic shape recovery (ER) was obtained using Equation 1 and the shape recovery owing to memory effect (SR) was calculated using Equation 2. The total shape recovery (TR) is referred to as the sum of the two contributions $(\mathrm{ER}+\mathrm{SR})$.

$$
\begin{aligned}
& E R=\left(\frac{L_{E R}-L_{\varepsilon 4 \%}}{L_{0}-L_{\varepsilon 4 \%}}\right) \times 4 \\
& S R=\left(\frac{L_{S R}-L_{E R}}{L_{0}-L_{\varepsilon 4 \%}}\right) \times 4
\end{aligned}
$$

Where: $\mathrm{L}_{0}$ is the initial length of the sample; $\mathrm{L}_{\varepsilon 4 \%}$ is the length of the sample after $4 \%$ compressive strain; $\mathrm{L}_{\mathrm{ER}}$ is the length of the sample after unloading; $\mathrm{L}_{\mathrm{SR}}$ is the length of the sample after annealing at $600^{\circ} \mathrm{C} / 30 \mathrm{~min}$, followed by water cooling.

\section{Results and discussions}

\subsection{Microstructural evolution}

In order to evaluate the effect of microstructural features like grain size and second-phase particles on the martensitic transformation, a detailed characterisation of samples under different processing conditions was conducted as follows: ST; $\mathrm{ST}+2 \mathrm{ECAE}$ passes; $\mathrm{ST}+2 \mathrm{ECAE}+$ annealing temperatures.

Fig. 1 exhibits electron micrographs of the ST sample. As seen in Fig. 1a, the microstructure is composed of large austenitic grains $(\sim 80 \mu \mathrm{m})$, presenting a $35 \%$ volume fraction of thermally induced martensite measured by XRD.

Under this condition (large grains), the martensite plates exhibited multi-variant orientation inside the grains, as seen at the centre grain in Fig. 1b. In stainless Fe-Mn-Si based shape memory steels, the $\gamma$ (fcc) $\leftrightarrow \varepsilon$ (hcp) martensitic transformation occurs through the movement of Shockley partial dislocations along every second (111) plane, toward the $[112]_{\gamma}$ direction, resulting in shear stress in the austenitic parent phase ${ }^{18}$. According to ${ }^{13,19}$, in coarse grains the Shockley partial dislocations need to travel long distances between grain boundaries in order to form martensite plates, accumulating large elastic strain energy. Depending upon the energetic balance, the shear stress can be relieved by the nucleation of new martensite variants (energetically favoured) instead 


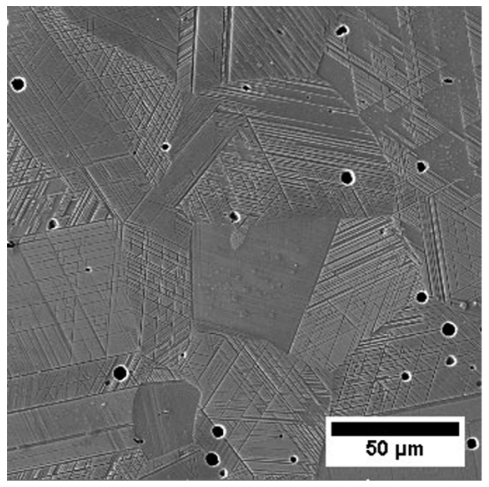

(a)

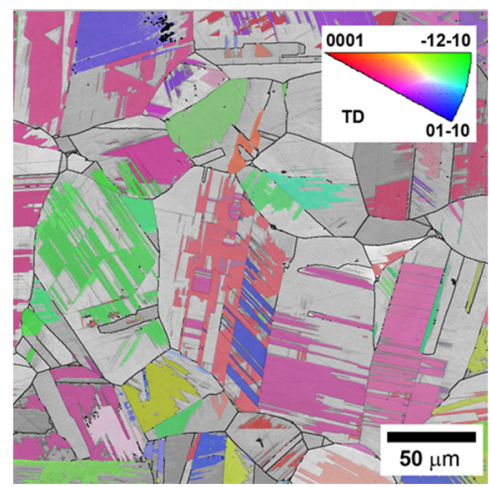

(b)

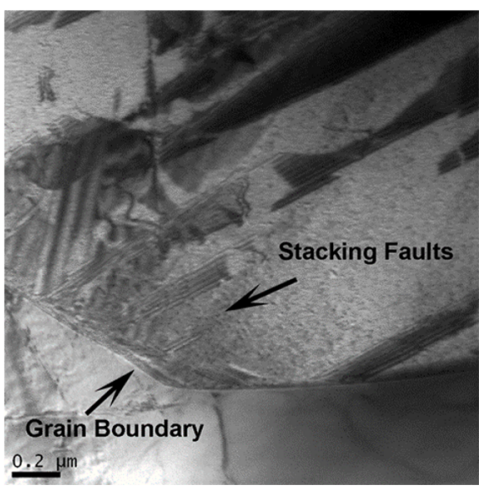

(c)

Figure 1. Micrographs of the ST sample: (a) SEM-SE, (b) Pattern Quality Map overlaid with a Martensite IPF Map (EBSD), (c) TEM-BF.

of traveling all the way from one grain boundary to another. This mechanism could explain the high volume fraction of multivariant martensite observed in the ST samples since new martensite plates would be continuously nucleated in order to relieve the stress generated by the growth of the preexisting plates. Furthermore, a closer look also revealed a large quantity of stacking faults distributed in the microstructure, especially at the grain boundaries (Fig. 1c), which act as embryos for the growth of the new martensite plates ${ }^{20}$.

Fig. 2 presents the micrograph of ST +2 ECAE sample. The microstructure is composed of elongated grains (Fig. $2 \mathrm{a})$, presenting deformation heterogeneities and mechanical twins (Fig. 2b). TEM observations also showed dislocations (Fig. 2c) and mechanical micro twins (Fig. 2d), generated by ECAE processing. According to ${ }^{21,22}$, mechanical twins are formed as an alternative deformation mechanism in alloys with low stacking fault energy, where the low mobility of Shockley partial dislocations prevents mechanisms such as dislocation cross-slip and climbing. As shown in Fig. 2d, the mechanical twins are usually formed in different $\{111\}$ austenitic planes, intercepting one another, owing to different orientations. This is a common feature of ECAE processed stainless steels by route $\mathrm{Bc}$, since alternate shear planes are activated during the subsequent passes ${ }^{22,23}$. The intersection between mechanical twins promotes the formation of twin boundaries, which, like grain boundaries, increase the mechanical resistance ${ }^{21}$. These microstructural constituents (dislocations, mechanical twins) probably decrease the mobility of Shockley partial dislocations, preventing the martensitic transformation, since no martensitic peaks were detected in the XRD analysis, Fig. 2e.

The ECAE processed samples were annealed for one hour at temperatures ranging from $650^{\circ} \mathrm{C}$ to $950^{\circ} \mathrm{C}$ in $100^{\circ} \mathrm{C}$ steps. As observed in Fig. $3 \mathrm{a}$, the annealing at $650^{\circ} \mathrm{C}$ promoted the nucleation of fine second-phase particles (diameter $\sim 0.20 \mu \mathrm{m}$ ), mainly along the original austenite grain boundaries and at prior deformation bands (area fraction of approximately $4 \%$ ). The subsequent annealing treatment, conducted at $750^{\circ} \mathrm{C}$, resulted in nucleation of small new grains of approximately $8 \mu \mathrm{m}$ (partial recrystallisation), as well as the increase in area fraction $(10 \%)$ and diameter of the second-phase particles $(0.26 \mu \mathrm{m})$, Fig. $3 \mathrm{~b}$. The complete recrystallisation was observed after the annealing treatment performed at $850^{\circ} \mathrm{C}$, Fig. $3 \mathrm{c}$, resulting in an average grain size of $5 \mu \mathrm{m}$ and concomitant coarsening of the second-phase particles $($ diameter $=0.7 \mu \mathrm{m}$ and area fraction of $8 \%$ ). Fig. $3 \mathrm{~d}$ shows the selected area diffraction patterns (SADP) taken from the precipitates in the $[\mathrm{T} 23]_{\mathrm{bcc}}$ and $[\mathrm{T} 12]_{\mathrm{bcc}}$ zone axis. As can be seen, the second-phase particles exhibited a bcc crystal structure with a lattice parameter of $0.875 \mathrm{~nm}$ and they were identified as $\chi$ phase, in agreement with ${ }^{24,25}$. The EDS analysis indicated that the $\chi$ phase particles were enriched in $\mathrm{Cr}$ and $\mathrm{Si}$, compared to the surrounding matrix and to the ST starting condition, as shown in Table 1. It is important to note that in these circumstances, small grain size and second-phase particles, the volume fraction of martensite estimated by XRD is around $5 \%$.

Fig. 4 presents SEM and EBSD micrographs of the $\mathrm{ST}+2 \mathrm{ECAE}+950^{\circ} \mathrm{C}$ sample. As can be seen in Fig. 4a, the microstructure is still heterogeneous, composed of regions containing coarse grains and regions containing small grains and second-phase particles. Compared to the previous sample annealed at $850^{\circ} \mathrm{C}$, the increase in the annealing temperature to $950^{\circ} \mathrm{C}$ promoted the coarsening (diameter $=1.3 \mu \mathrm{m})$ and partial dissolution of the $\chi$ phase particles (area fraction $=2.5 \%$ ) and those that remained were located mainly at grain boundaries in the fine grains region, hindering the grain growth. An increase in the volume fraction of $\varepsilon$ martensite to $21 \%$ was also observed, which exhibited multivariant morphology and was mainly formed in the region of coarse grains, Fig. 4b. Although in a small quantity, some monovariant martensite plates were observed within the finer grains region. However, according to previous works ${ }^{13,26}$, the decrease in the grain size would improve shape recovery owing to the shape memory effect and, therefore, a pronounced monovariant $\gamma$ to $\varepsilon$ phase transformation at the small grain sizes region was expected, but this did not happen. This behaviour could be explained considering that 


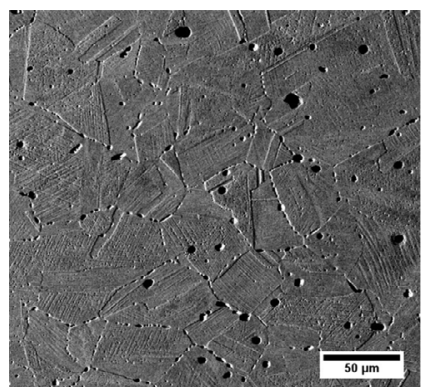

(a)

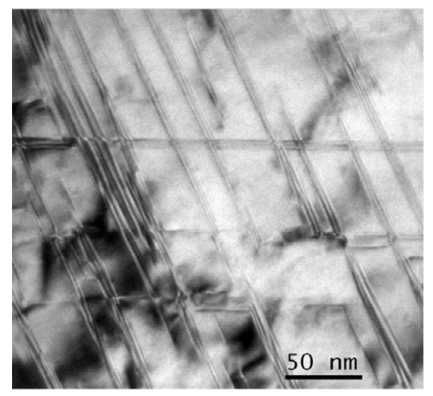

(d)

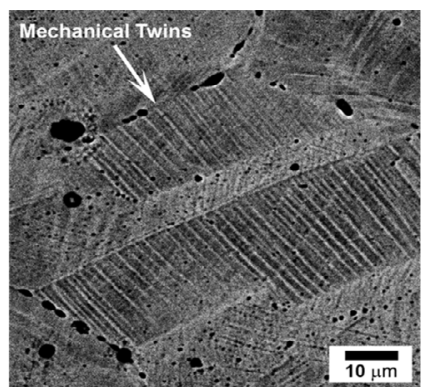

(b)

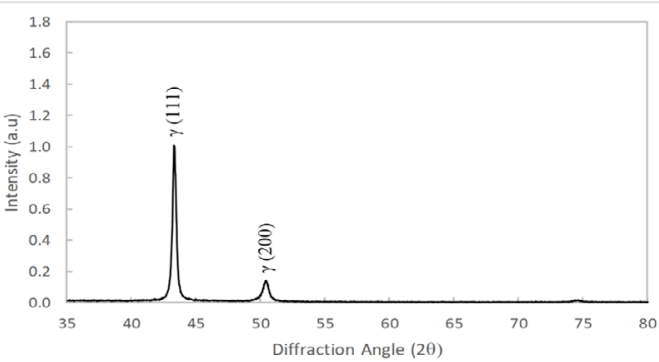

(e)

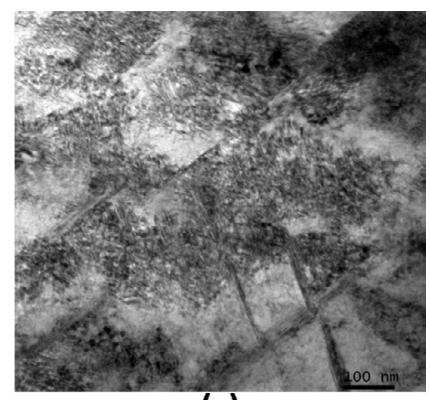

(c)

Figure 2. Micrographs of the ST + 2ECAE sample: (a) and (b) SEM-BSE; (c) and (d) TEM-BF, (e) X-Ray Diffraction Pattern.

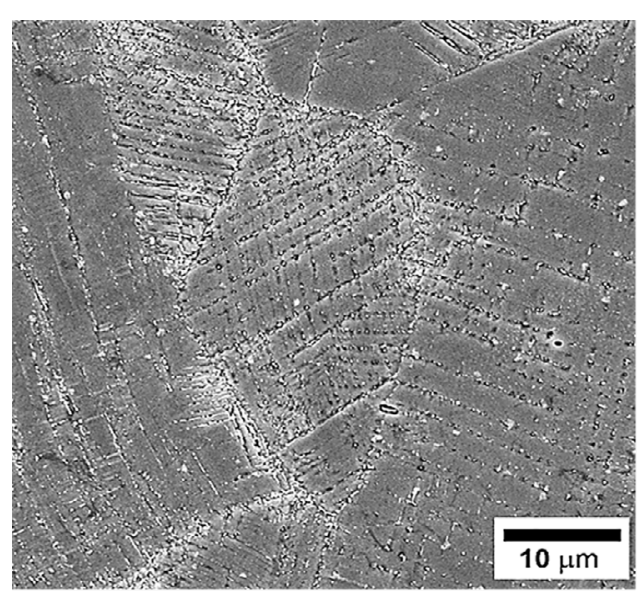

(a)

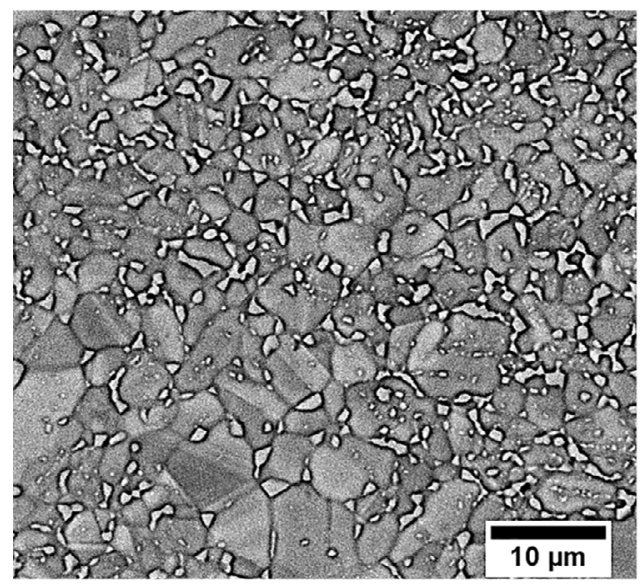

(c)

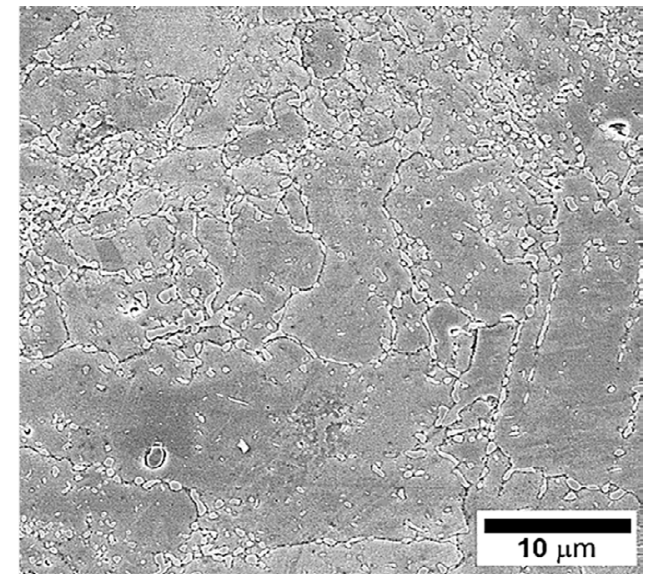

(b)

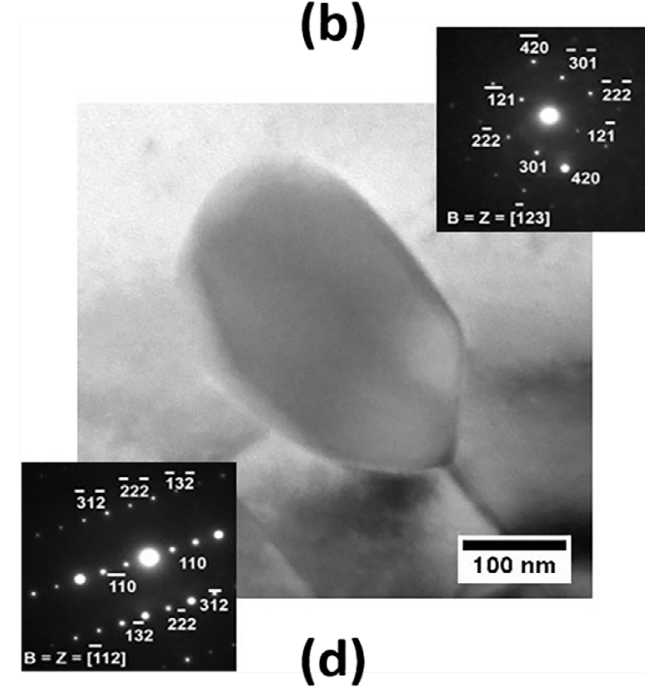

Figure 3. (a) sample $\mathrm{ST}+2 \mathrm{ECAE}+650^{\circ} \mathrm{C}$ (SEM-SE), (b) sample $\mathrm{ST}+2 \mathrm{ECAE}+750^{\circ} \mathrm{C}$ (SEM-SE), (c) sample $\mathrm{ST}$ $+2 \mathrm{ECAE}+850^{\circ} \mathrm{C}(\mathrm{SEM}-\mathrm{BSE})(\mathrm{d}) \mathrm{TEM}-\mathrm{BF}$ and SADP of the $\chi$ phase particle in the $[\overline{1} 23]_{\mathrm{bcc}}$ and $[\overline{1} 12]_{\mathrm{bcc}}$ zone axis. 
Table 1. Chemical compositions of ST (starting material), austenite matrix and $\chi$ phase particles after ST $+2 \mathrm{ECAE}+750^{\circ} \mathrm{C}$ (in wt $\%$ ) (TEM-EDS).

\begin{tabular}{cccccccc}
\hline Condition & & $\mathrm{Mn}$ & $\mathrm{Si}$ & $\mathrm{Cr}$ & $\mathrm{Ni}$ & $\mathrm{Co}$ & $\mathrm{Fe}$ \\
\hline \multicolumn{1}{c}{$\mathrm{ST}$} & & 8.26 & 5.25 & 12.80 & 5.81 & 11.84 & 56.04 \\
$\mathrm{ST}+2 \mathrm{ECAE}$ & Matrix & 9.44 & 4.42 & 13.58 & 5.34 & 11.46 & 55.76 \\
$+750^{\circ} \mathrm{C}$ & $\chi$ phase & 9.79 & 8.85 & 14.36 & 6.43 & 12.53 & 48.03 \\
\hline
\end{tabular}

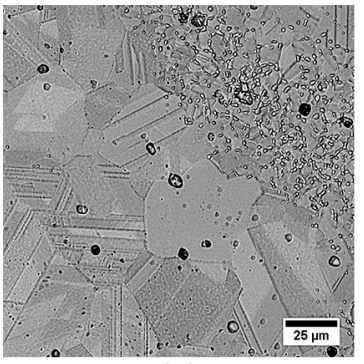

(a)

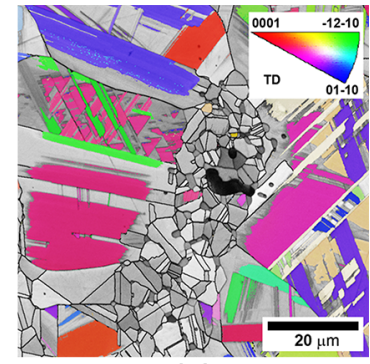

(b)
Figure 4. Micrographs of the $\mathrm{ST}+2 \mathrm{ECAE}+950^{\circ} \mathrm{C}$ sample: (a) SEM-SE, (b) Pattern Quality Map overlaid with a Martensite IPF Map - EBSD (ND-TD).

the $\gamma \rightarrow \varepsilon$ martensitic transformation presents a positive volume variation. Therefore, the strengthening of the austenite parent phase due to grain refinement and precipitation of second-phase particles, promoted an increase in the counterforce preventing volume expansion, consequently resulting in suppression of the martensitic transformation ${ }^{27,28}$.

\subsection{The relationship between microstructure, volume fraction of martensite and mechanical and shape-memory properties}

As presented in section 2.1, severe plastic deformation followed by annealing causes remarkable changes in the microstructure, which in turn, influence the martensitic phase transformation. To correlate the microstructural characteristics with the volume fraction of martensite and shape memory properties, compression tests and XRD analyses were performed in three processing conditions: $\mathrm{ST}$, $\mathrm{ST}+2 \mathrm{ECAE}+650^{\circ} \mathrm{C}$ and $\mathrm{ST}+2 \mathrm{ECAE}+950^{\circ} \mathrm{C}$, Fig. 5.

The following parameters were recorded: compressive yield stress $\left(\boldsymbol{\sigma}_{0.2} \%\right.$, elastic shape recovery upon unloading (ER), shape recovery owing to the shape memory effect upon heating at $600^{\circ} \mathrm{C}(\mathrm{SR})$, total shape recovery $(\mathrm{TR}=\mathrm{ER}+\mathrm{SR})$, volume fraction of thermally-induced martensite $\left(\mathrm{VE}_{\mathrm{T}}\right)$, volume fraction of martensite after $4 \%$ strain $\left(V \varepsilon_{4 \%}\right)$ and volume fraction of stress-induced martensite $\left(\Delta \varepsilon=V \varepsilon_{4 \%}-V \varepsilon_{\mathrm{T}}\right)$, as summarised in Table 2.

As shown in Fig. 5a, in the ST condition, the compressive yield stress was $310 \mathrm{MPa}$ and, in this case, the total shape recovery was $1.75 \%$, comprised of a shape recovery owing to memory effect of $1.45 \%$ and an elastic shape recovery of $0.30 \%$. The volume fraction of thermally induced martensite was approximately $35 \%$, which increased to $62 \%$ after 4 $\%$ compressive strain, that is, $\Delta \varepsilon=27 \%$ of stress-induced

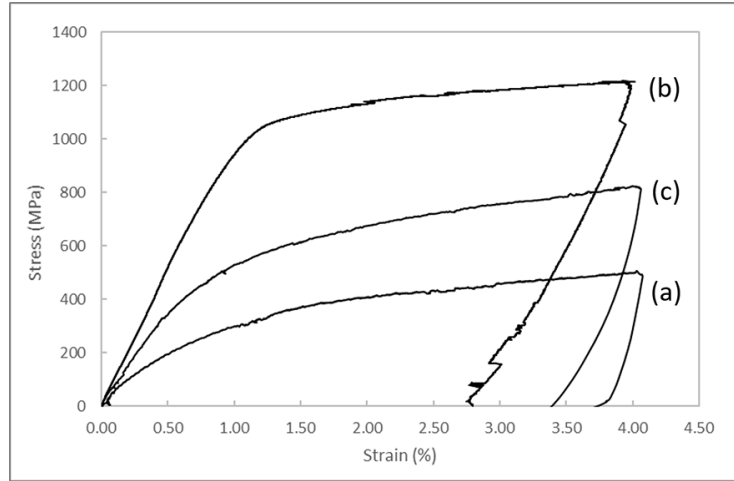

Figure 5. Stress $x$ Strain curves: (a) ST, (b) $\mathrm{ST}+2 \mathrm{ECAE}+650^{\circ} \mathrm{C}$, (c) $\mathrm{ST}+2 \mathrm{ECAE}+950^{\circ} \mathrm{C}$.

martensite, Fig 6. As can be seen in Table 2, the ST condition resulted in the highest volume fraction of thermally and stress induced martensite, as well as in the highest shape recovery owing to memory effect. Considering that the direct and reverse martensitic transformations (thermally or stress induced) are related to the mobility of the $\gamma \leftrightarrow \varepsilon$ interfaces, the ST condition should be the most favourable condition for such movements. In the ST condition, as seen in Fig 1, the sample presented a clean, precipitate-free microstructure with no deformation defects that would hinder the forward and backward movement of Shockley partial dislocations, enhancing the reversibility of martensitic transformation. The easiness of inducing martensite was also corroborated by the lowest value of the yield stress, which is the stress necessary to mechanically induce the martensite.

For the sample $\mathrm{ST}+2 \mathrm{ECAE}+650^{\circ} \mathrm{C}$, a considerable increase in mechanical resistance was noticed as compared to the ST condition, from $310 \mathrm{MPa}$ to $1080 \mathrm{MPa}$, Fig. 5. The high value of yield stress indicated the difficulty of stress-inducing the martensite, which was corroborated by the significant decrease in the volume fractions of thermally-induced (5 $\%$ ) and stress-induced ( $8 \%$ ) martensite as compared to the ST condition, Fig. 7. Interestingly, this was the condition of highest total shape recovery $(2.10 \%)$, but the major contribution came from the elastic shape recovery $(1.25 \%)$. As can be seen in Fig 3a, the ECAE processing, followed by the annealing at $650^{\circ} \mathrm{C}$, resulted in a microstructure composed of deformation defects and second-phase particles, which acted as a pinning centre for the stress-induced martensite plates, generating the back stress necessary to promote the backward movement of Shockley partial dislocations and, consequently, the elastic shape recovery. In this case, one could 
Table 2. Compressive yield stress $\left(\sigma_{0.2 \%}\right)$, elastic shape recovery (ER), shape memory recovery (SR), total shape recovery (TR), volume fraction of thermally-induced martensite $\left(V \varepsilon_{\mathrm{T}}\right)$, martensite after $4 \%$ compressive strain $\left(\mathrm{V} \varepsilon_{4 \%}\right)$ and stress-induced martensite $\left(\Delta_{\varepsilon}\right)$.

\begin{tabular}{cccccccc}
\hline Sample Condition & $\sigma_{0.2 \%}(\mathrm{MPa})$ & $\mathrm{ER}(\%)$ & $\mathrm{SR}(\%)$ & $\mathrm{TR}(\%)$ & $\mathrm{V}_{\mathrm{T}}(\%)$ & $\mathrm{V} \varepsilon_{4 \%}(\%)$ & $\Delta_{\varepsilon}(\%)$ \\
\hline $\mathrm{ST}$ & 310 & 0.30 & 1.45 & 1.75 & 35 & 62 & 27 \\
$\mathrm{ST}+2 \mathrm{ECAE}+650^{\circ} \mathrm{C}$ & 1080 & 1.25 & 0.85 & 2.10 & 5 & 13 & 8 \\
$\mathrm{ST}+2 \mathrm{ECAE}+950^{\circ} \mathrm{C}$ & 560 & 0.60 & 1.38 & 1.98 & 21 & 43 & 22 \\
\hline
\end{tabular}

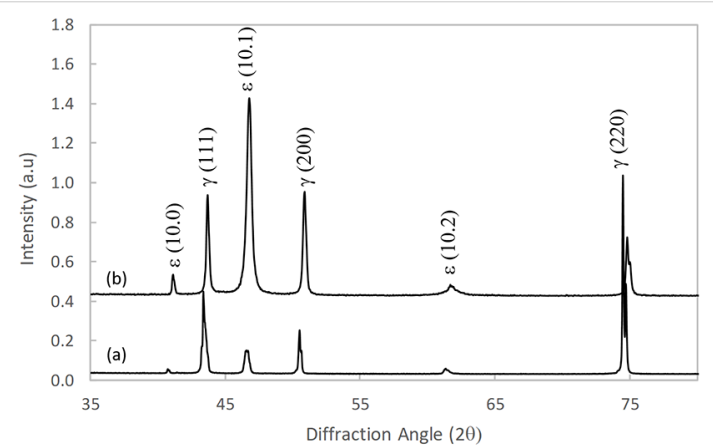

Figure 6. X-Ray Diffraction Patterns: (a) ST, (b) ST $+4 \%$ compressive strain.

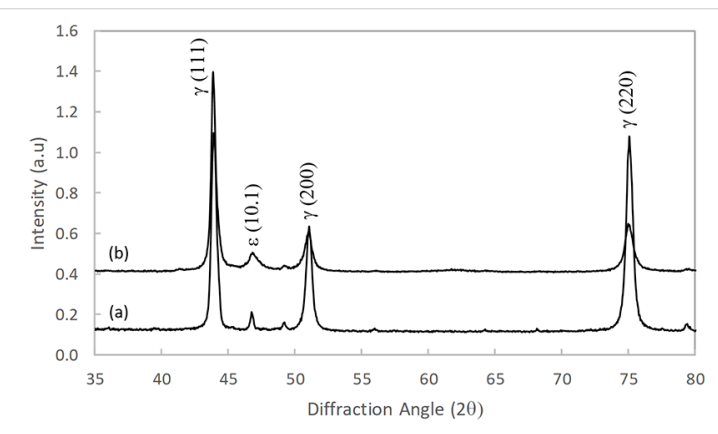

Figure 7. X-Ray Diffraction Patterns: (a) $\mathrm{ST}+2 \mathrm{ECAE}+650^{\circ} \mathrm{C}$, (b) $\mathrm{ST}+2 \mathrm{ECAE}+650^{\circ} \mathrm{C}+4 \%$ compressive strain.

infer that if the volume fraction of stress-induced martensite was measured in situ as the compressive strain progressed, its values would be proportional to the imposed strain.

For the sample $\mathrm{ST}+2 \mathrm{ECAE}+950^{\circ} \mathrm{C}$, the yield stress $(560 \mathrm{MPa})$ was almost twice that of the ST condition (310MPa) and approximately half of that annealed at $650^{\circ} \mathrm{C}$ $(1080 \mathrm{MPa})$. Coincidentally, the elastic shape recovery, ER $(0.60 \%)$, was also twice that of the ST condition $(0.30$ $\%)$ and half that of the sample annealed at $650^{\circ} \mathrm{C}(1.25$ $\%)$. On the other hand, the shape memory effect (1.38\%) was close to that of the ST condition (1.45\%), resulting in a total shape recovery of $2.00 \%$. In this condition, an increase in the volume fractions of thermally-induced (21 $\%$ ) and stress-induced martensite (22\%) was observed, Fig 8 , in comparison to the previous heat treatment. Thus, the sample annealed at $950^{\circ} \mathrm{C}$ presented an intermediary behaviour between the ST and that annealed at $650^{\circ} \mathrm{C}$. As shown in Fig 4, its microstructure, although completely recrystallised, was still heterogeneous, presenting regions

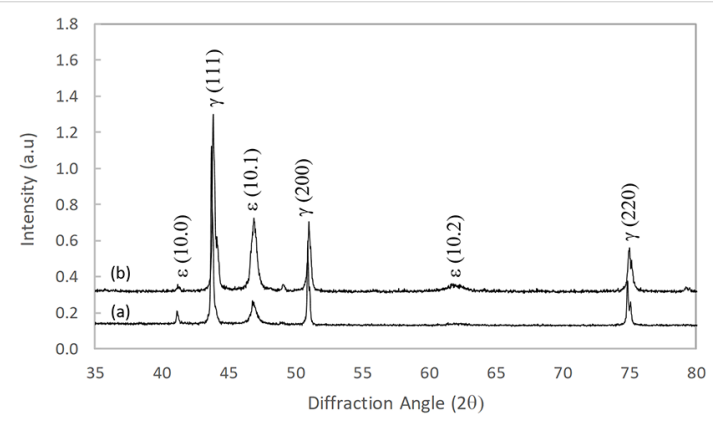

Figure 8. X-Ray Diffraction Patterns: (a) $\mathrm{ST}+2 \mathrm{ECAE}+950^{\circ} \mathrm{C}$, (b) $\mathrm{ST}+2 \mathrm{ECAE}+950^{\circ}+4 \%$ compressive strain.

with coarse grains containing multivariant martensite plates and regions of fine grains with few monovariant martensite plates and $\chi$ phase particles. Therefore, during compressive strain, stress-induced martensite plates were formed in the regions of coarse grains, while the regions of fine grains provided the back-stress related to elastic shape recovery.

The above results showed that the shape memory properties are essentially related to the mechanical resistance of the austenitic parent phase. When the mechanical resistance (indicated by the yield stress $\left(\sigma_{0.2 \%}\right)$ ) is low, the major contribution to total shape recovery comes from the shape memory effect (ST sample). Therefore, in order to increase shape recovery due to the memory effect, a "clean" microstructure should be produced. This will facilitate the forward and backward movement of Shockley partial dislocations, that is, increase the reversibility of martensitic transformation. Inversely, the increase in the mechanical resistance promotes a proportional increase of the elastic shape recovery $(\gamma \leftrightarrow($ transformation), since atoms in solid solution, deformation defects and precipitates prevent pseudo-plastic deformation. This behaviour has been observed in different stainless shape memory steel types, as shown in previous works developed by our research group ${ }^{12,29}$.

\section{Conclusions}

This work evaluated the influence of the microstructure and mechanical resistance on the shape memory properties of ECAE processed stainless Fe-Mn-Si-Cr-Ni-Co steel. The main remarks are:

- The solution treated samples exhibited a high volume fraction of thermally and stress-induced martensite, indicating that a microstructure composed of large 
grains, free of precipitates and deformation defects facilitate the forward and backward movements of the Shockley partial dislocations, and consequently leads to good shape memory effect.

- On the other hand, deformation defects and second phase particles act as pinning centres, preventing the growth of martensite plates. As a result, a back-stress is generated during deformation, which promotes the reverse transformation of martensite to austenite during unloading, resulting in high values of elastic shape recovery.

- In summary, the shape memory properties are essentially related to the mechanical resistance of the parent phase. Increasing the mechanical resistance due to grain refinement and precipitation of second phase particles promotes a proportional increase of the elastic shape recovery, and a concomitant reduction of the shape memory effect. Reversely, clean microstructure improves the shape recovery due to shape memory effect.

\section{Acknowledgements}

Authors are grateful to FAPESP (Grants 2000/09730-1; 2009/09091-3; 2010/20565-4), CNPq (Grants no 475194/2011-0 and 552199/2011-7), FINEP/PRO-INFRA, Villares Metals SA, IEAv and CNPEM/LNNano (Quanta-14851, Quanta-13576, SEM-17716) and IPEN.

\section{References}

1. Otsuka K, Wayman CM, eds. Shape Memory Materials. Cambridge: Cambridge University Press; 1998.

2. Bergeon N, Kajiwara S, Kikuchi T. Atomic force microscope study of stress-induced martensite formation and its reverse transformation in a thermomechanically treated Fe-Mn-Si-CrNi alloy. Acta Materialia. 2000;48(16):4053-4064.

3. Jani JM, Leary M, Subic A, Gibson MA. A review of shape memory alloy research, applications and opportunities. Materials \& Design (1980-2015). 2014;56:1078-1113.

4. Tsuzaki K, Natsume Y, Tomota Y, Maki T. Effect of solution hardening on the shape memory effect of Fe-Mn based alloys. Scripta Metallurgica et Materialia. 1995;33(7):1087-1092.

5. Ariapour A, Yakubtsov I, Perovic DD. Effect of nitrogen on shape memory effect of a Fe-Mn-based alloy. Materials Science and Engineering: A. 1999;262(1-2):39-49.

6. Kajiwara S, Liu D, Kikuchi T, Shinya N. Remarkable improvement of shape memory effect in Fe-Mn-Si based shape memory alloys by producing $\mathrm{NbC}$ precipitates. Scripta Materialia. 2001;44(12):2809-2814.

7. Baruj A, Kikuchi T, Kajiwara S. TEM observation of the internal structures in $\mathrm{NbC}$ containing $\mathrm{Fe}-\mathrm{Mn}$-Si-based shape memory alloys subjected to pre-deformation above room temperature. Materials Science and Engineering: A. 2004;378(1-2):337-342.
8. Dong ZZ, Kajiwara S, Kikuchi T, Sawaguchi T. Effect of predeformation at room temperature on shape memory properties of stainless type $\mathrm{Fe}-15 \mathrm{Mn}-5 \mathrm{Si}-9 \mathrm{Cr}-5 \mathrm{Ni}-(0.5-1.5) \mathrm{NbC}$ alloys. Acta Materialia. 2005;53(15):4009-4018.

9. Yang CH, Lin HC, Lin KM. Improvement of shape memory effect in Fe-Mn-Si alloy by slight tantalum addition. Materials Science and Engineering: A. 2009;518(1-2):139-143.

10. Kubo H, Nakamura K, Farjami S, Maruyama, T. Characterization of Fe-Mn-Si-Cr shape memory alloys containing VN precipitates. Materials Science and Engineering: A . 2004;378(1-2):343-348.

11. Stanford N, Dunne DP. Effect of NbC and TiC precipitation on shape memory in an iron-based alloy. Journal of Materials Science. 2006;41(15):4883-4891.

12. Käfer KA, Bernardi HH, Naito LKF, de Lima NB, Otubo J. Shape Memory Properties of Ultrafine-Grained Austenitic Stainless Steel. Materials Science Forum. 2013;738-739:496500 .

13. Otubo J, Nascimento FC, Mei PR, Cardoso LP, Kaufman MJ. Influence of Austenite Grain Size on Mechanical Properties of Stainless SMA. Materials Transactions. 2002;43(5):916-919.

14. Furukawa M, Iwahashi Y, Horita Z, Nemoto M, Langdon TG. The shearing characteristics associated with equal-channel angular pressing. Materials Science and Engineering: A. 1998;257(2):328-332.

15. ASTM International. ASTM E112-13 - Standard Test Methods for Determining Average Grain Size. West Conshohocken: ASTM International; 2013.

16. Image Process and Analysis in Java (Image J). Available from: <http://imagej.nih.gov/ij/>. Access in: 15/11/2015.

17. Materials Analysis Using Diffraction Software (MAUD). Available from: $<$ http://maud.radiographema.com $>$. Access in: $22 / 12 / 2015$.

18. Yang JH, Wayman CM. On secondary variants formed at intersections of e martensite variants. Acta Metallurgica et Materialia. 1992;40(8):2011-2023.

19. Takaki S, Nakatsu H, Tokunaga Y. Effects of Austenite Grain Size on e Martensite Transformation in Fe- 15 mass $\% \mathrm{Mn}$ Alloy. Materials Transactions JIM. 1993;34(6):489-495.

20. Inagaki $H$. Transmission electron microscopy of the shape memory phenomena in $\mathrm{Fe}-14 \% \mathrm{Mn}-6 \% \mathrm{Si}-9 \% \mathrm{Cr}-6 \% \mathrm{Ni}$ alloy polycrystals. Zeitschrift für Metallkunde. 1992;83(2):97104.

21. Tsakiris V, Edmonds DV. Martensite and deformation twinning in austenitic steels. Materials Science and Engineering. A. 1999;273-275:430-436.

22. Yapici GG, Karaman I, Luo ZP, Maier HJ, Chumlyakov YI. Microstructural refinement and deformation twinning during severe plastic deformation of $316 \mathrm{~L}$ stainless steel at high temperatures. Journal of Materials Research. 2004;19(8):2268-2278.

23. Ueno H, Kakihata K, Kaneko Y, Hashimoto S, Vinogradov A. Enhanced fatigue properties of nanostructured austenitic SUS 316L stainless steel. Acta Materialia. 2011;59(18):70607069. 
24. Lin HC, Lin CS, Lin KM, Chuang YC. An investigation of grain-boundary phase in $\mathrm{Fe}-30 \mathrm{Mn}-6 \mathrm{Si}-5 \mathrm{Cr}$ shape memory alloy. Journal of Alloys and Compounds. 2001;319(1-2):283-289.

25. Stanford N, Dunne DP, Monaghan BJ. Austenite stability in Fe-Mn-Si-based shape memory alloys. Journal of Alloys and Compounds. 2007;430(1-2):107-115.

26. Nascimento FC, Mei PR, Cardoso LP, Otubo J. Grain size effect on the structural parameters of the stress induced ehcp - martensite in iron-based shape memory alloy. Materials Research. 2008; 11(1): 63-67.
27. Kajiwara S. Roles of dislocations and grain bondary in the martensite nucleation. Metallurgical and Materials Transactions A. 1986;17(10):1693-1702.

28. Nichol TJ, Judd G, Ansell GS. The relation between austenite strength and the transformation to martensite in Fe-10 pct Ni-0.6 pct C alloys. Metallurgical Transactions A. 1977;8(12):18771883.

29. Andrade EC, Bernardi HH, Otubo J. Microstructural evaluation on shape recovery in stainless Fe-Mn-Si-Cr-Ni-Co SMA processed by wire drawing. Materials Research. 2014;17(3):583-587. 